\title{
Fracture initiation in elastic brittle materials having non-linear fracture envelopes
}

\author{
NICHOLAS J. ALTIERO and DAVID L. SIKARSKIE \\ Department of Aerospace Engineering, University of Michigan, Ann Arbor, Michigan 48105, U.S.A.
}

(Received January 11, 1974; in revised form September 20, 1974)

\begin{abstract}
A theory is outlined for determining the initiation of fracture and initial fracture propagation in elastic brittle materials having non-linear Mohr fracture envelopes. This theory is applied to a specific boundary value problem, i.e. a truncated quarter plane with arbitrary traction distribution on the truncated boundary and varyingeconfining pressure. This problem simulates the chipping phase of the penetration of a wedge shaped tool into an elastic brittle material. Numerical results are obtained for two rock materials, Blair dolomite and quartzite.

Results indicate that for increasing confining pressure, a limit condition is reached for both fracture initiation location and force. This limit location is closer to the boundary than the fracture initiation points at lower confining pressures, indicating smaller chips. It is also found that initial fracture propagation is less clearly defined at higher confining pressures. Both of these results have been observed experimentally.
\end{abstract}

\section{Nomenclature}

\begin{tabular}{|c|c|}
\hline$C_{A}$ & asymptotic value of Mohr envelope \\
\hline$C\left(\bar{\sigma}_{\mathrm{m}}\right)$ & $\begin{array}{l}\bar{\tau} \text {-intercept of a linear envelope tangent to the Mohr envelope } \\
\text { at the point where the mean stress is } \bar{\sigma}_{\mathrm{m}}\end{array}$ \\
\hline$K\left(\bar{\sigma}_{1}^{T}, \bar{\sigma}_{2}^{T} ; \mu\left(\bar{\sigma}_{\mathrm{m}}\right), C\left(\bar{\sigma}_{\mathrm{m}}\right)\right)$ & fracture function \\
\hline$K_{\min }$ & defines point of fracture initiation \\
\hline$L$ & $\begin{array}{l}\text { length of the truncated boundary; characteristic length for the } \\
\text { problem }\end{array}$ \\
\hline$m$ & traction "form" parameter \\
\hline$P$ & $\begin{array}{l}\text { total vertical line load on the truncated quarter plane (half the } \\
\text { wedge force) }\end{array}$ \\
\hline$p$ & scalar reference pressure \\
\hline$t_{n}, t_{s}$ & normal, shear traction on truncated face \\
\hline$\alpha_{i}$ & coefficients in polynomial fit for $\bar{\tau}=\bar{\tau}\left(\bar{\sigma}_{\mathrm{m}}\right)$ \\
\hline$\beta_{i}$ & coefficients in polynomial fit for $\bar{\sigma}=\bar{\sigma}\left(\bar{\sigma}_{\mathrm{m}}\right)$ \\
\hline$\gamma_{1}$ & angle between $x$-axis and normal to first principal plane \\
\hline$\theta$ & half wedge angle \\
\hline$\xi$ & length coordinate along the slanted face \\
\hline & external coefficient of friction (between wedge and material) \\
\hline$\mu\left(\bar{\sigma}_{\mathrm{m}}\right)$ & $\begin{array}{l}\text { slope of linear envelope tangent to the Mohr envelope at the point } \\
\text { where the mean stress is } \bar{\sigma}_{\mathrm{m}}\end{array}$ \\
\hline $\bar{\sigma}_{1,2}, \sigma_{1,2}$ & $\begin{array}{l}\text { principal, dimensionless principal stresses }\left(\sigma_{1}>\sigma_{2}\right) \text { due to } \\
\text { wedge loading }\end{array}$ \\
\hline $\bar{\sigma}_{1,2}^{T}$ & total principal stresses $\left(\bar{\sigma}_{1}^{T}>\bar{\sigma}_{2}^{T}\right)$ \\
\hline $\bar{\sigma}$ & normal stress on a plane \\
\hline $\bar{\sigma}^{H}$ & hydrostatic stress \\
\hline $\begin{array}{l}\bar{\sigma}_{\mathfrak{m}}=\frac{1}{2}\left(\bar{\sigma}_{1}^{T}+\bar{\sigma}_{2}^{T}\right) \\
\bar{\tau}\end{array}$ & $\begin{array}{l}\text { mean stress } \\
\text { shear stress on a plane }\end{array}$ \\
\hline
\end{tabular}


$\phi_{f}$

$\phi\left(\bar{\sigma}_{\mathrm{m}}\right)$

$\psi_{1,2}$ external friction angle $\left(\mu_{f}=\tan \phi_{f}\right)$

$\mu\left(\bar{\sigma}_{\mathrm{m}}\right)=\tan \phi\left(\bar{\sigma}_{\mathrm{m}}\right)$

angles between $x$-axis and normals to Mohr planes

\section{Introduction}

In a previous paper [1], fracture initiation and subsequent growth were analyzed for elastic brittle materials which obeyed a linear (Coulomb-Mohr) fracture envelope. Due to the linearity of the fracture criterion it was possible to do a dimensionless parametric analysis valid for all materials having such a linear envelope. There are, however, many materials for which a linear fracture envelope is not a good representation. This non-linearity, as in other non-linear problems, precludes a single dimensionless solution. Here it is necessary that the specific fracture envelope be known.

In the present paper a general analysis is developed for fracture initiation in non-linear brittle materials and is applied to two such materials, Blair dolomite and quartzite. As in Ref. [1], the idealized boundary value problem studied is the truncated quarter-plane with a variable traction applied on the truncated face, see Fig. 1. Fracture initiation in such a region represents the first stage of chip formation and is important in a number of practical situations, e.g. drilling of hard rock. Of interest, also, and included in the analysis, is the effect of hydrostatic pressure on fracture initiation. This problem is of interest in drilling in the presence of large overburden pressures.

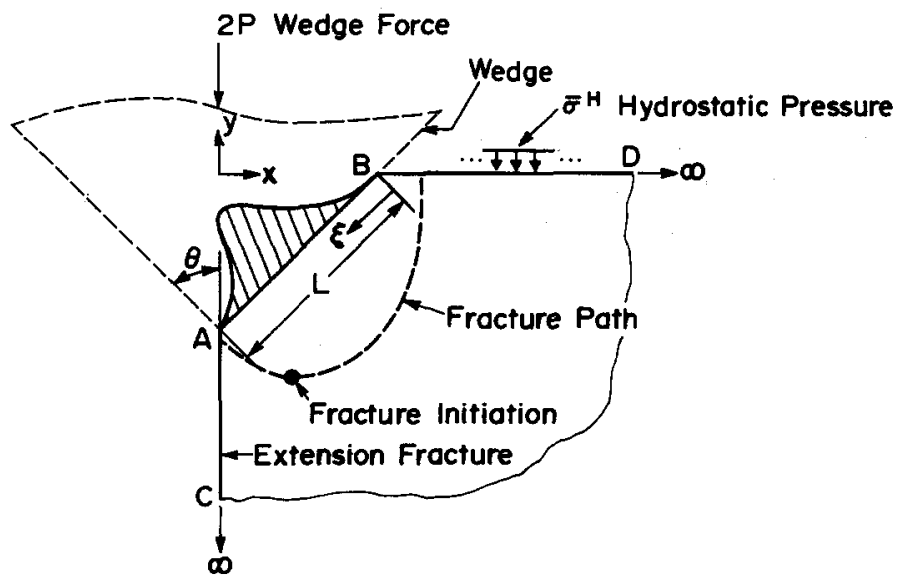

Figure 1. Problem geometry (symmetric about $y$-axis), after [1].

In Section 2, both a discussion of the physical significance and a quantitative description of the non-linear (Mohr) fracture envelope are presented. An iterative technique for handling non-linear fracture envelopes based on a series of linear envelopes is developed in Section 3. This first requires the solution of the elastic stress field based on an integral equation procedure and is discussed in detail in $[2,1]$. This technique is then applied to the two materials mentioned above and results obtained for varying hydrostatic pressure and truncation angle. These results are presented and discussed in Section 4.

\section{Fracture criterion}

\subsection{Discussion of the fracture criterion}

Mohr fracture envelopes have been used extensively in the study of the fracture of brittle materials [3]. In general, these envelopes are developed phenomenologically, i.e. the Mohr's 
circles to which the envelope is tangent are defined by "strength failure" of cylindrical test specimens under axial load and varying confining pressure. Thus, a criterion developed in this way does not define fracture initiation in the Griffith sense. It will be shown, however, that it is not fracture initiation in the Griffith sense, but rather crack coalescence that defines the onset of fracture in the present theory.

In Fig. 2 are plotted lateral, volumetric, and axial strain versus axial stress for a compression test on quartzite under zero confining pressure [4]. Of particular significance in explaining the microscopic behavior is the volumetric strain curve. This is interpreted as follows. Axial stresses in the vicinity of point $A$ are sufficient to initiate growth at a number of critically oriented Griffith cracks. It should be noted that the stress field is assumed globally uniform* (uniaxial) and the Griffith flaws are randomly distributed and are located, for example, at grain boundaries [6]. As the stress increases these cracks continue to grow. Such growth is indicated by a deviation from linearity of volumetric strain, i.e. dilatancy, see Fig. 2 . This

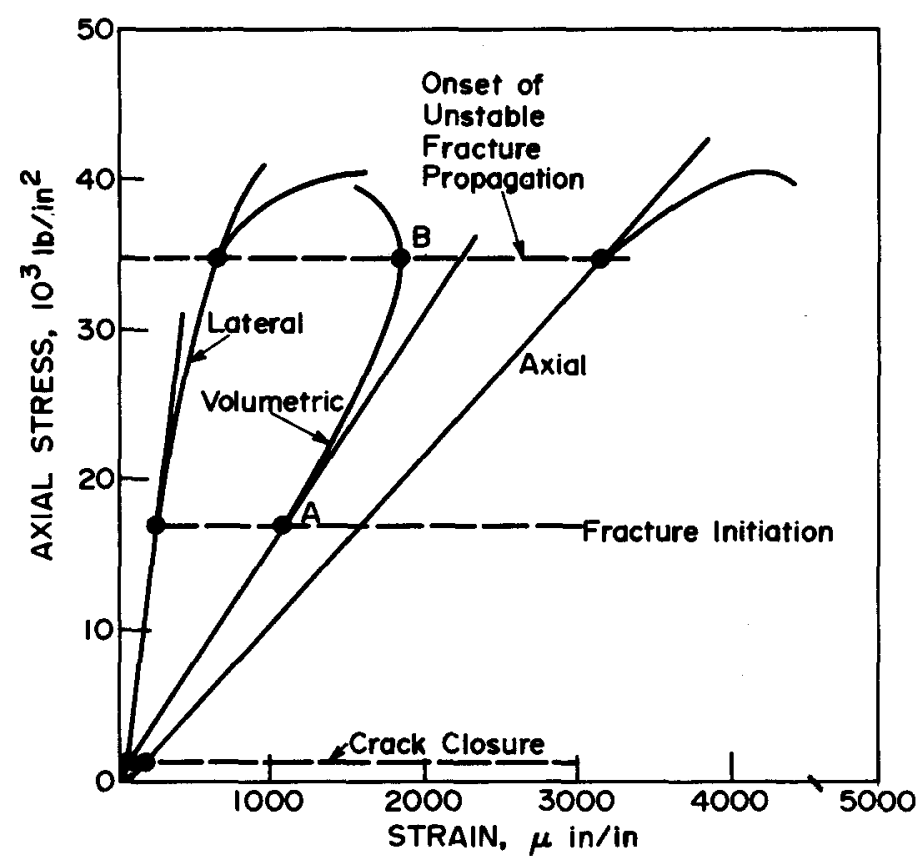

Figure 2. Relationship between axial stress and axial, lateral, and volumetric strain, for quartzite in uniaxial compression after [4].

dilatancy is an increase in porosity which is a reflection of internal damage resulting from crack growth. Further increase in stress begins to produce coalescence of these cracks. For stresses beyond point $B$ coalescence is extensive throughout the region as evidenced by large increases in dilatancy. This widespread damage is preliminary to the coalescence which forms the final fracture surface resulting in strength failure of the specimen. It is important to note that the axial and lateral stress-strain curves in Fig. 2 are fairly linear to point B. This indicates that the assumption of linear elasticity in the stress field calculation is reasonable.

The Griffith theory gives the stress level at which preferentially oriented cracks begin to grow while the final Mohr envelope indicates when such cracks have sufficiently coalesced to cause final strength failure. In the present boundary value problem (non-uniform global

* Most compression tests, in fact, produce non-uniform "global" stress states. The test specimens introduced by Brace [5] closely approximate a uniform stress state as evidenced by the uniform damage distribution in the specimen. 
stress field), of interest is the beginning of the fracture forming the resultant chip. Thus fracture initiation in the present theory is characterized by crack coalescence as differentiated from initiation in the Griffith sense and is most closely represented by the material strength failure (Mohr fracture envelope).

\subsection{Analytical description of Mohr envelopes}

The Mohr envelopes can be represented in the following form:

$$
|\bar{\tau}|+\mu\left(\bar{\sigma}_{\mathrm{m}}\right) \bar{\sigma}=C\left(\bar{\sigma}_{\mathrm{m}}\right)
$$

where $\bar{\tau}, \bar{\sigma}$ are the dimensional shear and normal stresses on some plane; $\mu\left(\bar{\sigma}_{\mathrm{m}}\right), C\left(\bar{\sigma}_{\mathrm{m}}\right)$ are the slope and intercept with the $\bar{\tau}$-axis of a linear envelope tangent to the Mohr envelope at the point whose mean stress is $\bar{\sigma}_{\mathrm{m}}$, see Fig. 3. From Fig. 3 the "material constants" $\mu\left(\bar{\sigma}_{\mathrm{m}}\right), C\left(\bar{\sigma}_{\mathrm{m}}\right)$ are given by:

$$
\begin{aligned}
& \mu\left(\bar{\sigma}_{\mathrm{m}}\right)=\left[\bar{\sigma}\left(\bar{\sigma}_{\mathrm{m}}\right)-\bar{\sigma}_{\mathrm{m}}\right] / \bar{\tau}\left(\bar{\sigma}_{\mathrm{m}}\right) \\
& C\left(\bar{\sigma}_{\mathrm{m}}\right)=\bar{\tau}\left(\bar{\sigma}_{\mathrm{m}}\right)+\mu\left(\bar{\sigma}_{\mathrm{m}}\right) \bar{\sigma}\left(\bar{\sigma}_{\mathrm{m}}\right) .
\end{aligned}
$$

The Mohr envelopes represent given input data and are further expressible parametrically in terms of the following polynomials:

$$
\begin{aligned}
& \bar{\tau}=\bar{\tau}\left(\bar{\sigma}_{\mathrm{m}}\right)=\Sigma_{0 \leqslant i \leqslant r} \alpha_{i} \bar{\sigma}_{\mathrm{m}}^{i} \\
& \bar{\sigma}=\bar{\sigma}\left(\bar{\sigma}_{\mathrm{m}}\right)=\Sigma_{0 \leqslant i \leqslant r} \beta_{i} \bar{\sigma}_{\mathrm{m}}^{i} .
\end{aligned}
$$

The two materials considered are Blair dolomite and quartzite. The Mohr envelope data for these two rocks were obtained by Brace [5] using the special compression specimens mentioned previously to insure uniformity of the axial stress distribution. With the envelopes given, the constants in Eqn. (3) can be found using a least squares fit, see Table 1. Details of this fitting including the computer program [7] are found in Ref. [10].

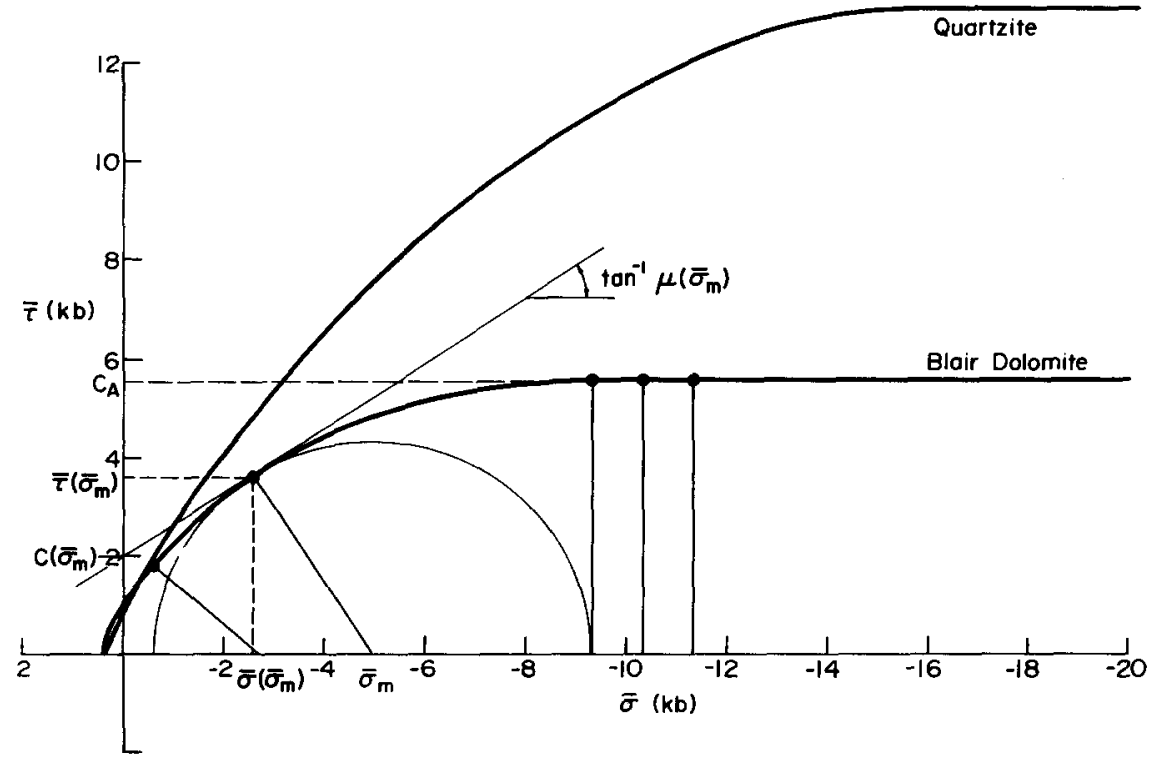

Figure 3. Mohr envelopes for Blair dolomite and quartzite (based on data from [5]). 
TABLE 1

Coefficients of least-squares polynomial fits

\begin{tabular}{lll}
\hline & Blair dolomite & quartzite \\
\hline$\alpha_{0}$ & -0.90932523 & 0.14589997 \\
$\alpha_{1}$ & -2.2527893 & -0.39293411 \\
$\alpha_{2}$ & -0.98623052 & -0.11661122 \\
$\alpha_{3}$ & -0.27366620 & -0.07536858 \\
$\alpha_{4}$ & -0.03557571 & -0.01643163 \\
$\alpha_{5}$ & -0.00211718 & -0.00168279 \\
$\alpha_{6}$ & -0.00004702 & -0.00008117 \\
$\alpha_{7}$ & 0.00000000 & -0.00000149 \\
$S$ & 0.058635 & 0.257773 \\
& & \\
$\beta_{0}$ & 0.64800776 & 0.37275022 \\
$\beta_{1}$ & 0.25671860 & 0.44518983 \\
$\beta_{2}$ & -0.22792865 & 0.32929945 \\
$\beta_{3}$ & -0.10632980 & 0.14898031 \\
$\beta_{4}$ & -0.02453351 & 0.02914393 \\
$\beta_{5}$ & -0.00222438 & 0.00282896 \\
$\beta_{6}$ & -0.00006876 & 0.00013247 \\
$\beta_{7}$ & 0.00000000 & 0.00000239 \\
$S$ & 0.113464 & 0.205440 \\
\hline
\end{tabular}

\section{Analysis}

A fracture mechanics analysis involves several steps. It is first necessary to determine the stress field due to the external loadings. This stress is then compared with a fracture criterion to determine the location and stress level at which fracture initiates. The next stage is fracture growth which in the present problem would terminate in the formation of a chip [1]. The main interest in the present paper is in the initiation of fracture. However, comments regarding initial fracture propagation are also made.

The criterion which governs here is the Mohr criterion given by Eqn. (1). If the planes which maximize the left-hand side of Eqn. (1) are found and the resulting stresses on these planes expressed in terms of principal stresses, Eqn. (1) takes the form,

$$
\left[\mu\left(\bar{\sigma}_{\mathrm{m}}\right) / 2\right]\left(\bar{\sigma}_{1}^{T}+\bar{\sigma}_{2}^{T}\right)+\left[1+\mu^{2}\left(\bar{\sigma}_{\mathrm{m}}\right)\right]^{\frac{1}{2}}\left(\bar{\sigma}_{1}^{T}-\bar{\sigma}_{2}^{T}\right) / 2=C\left(\bar{\sigma}_{\mathrm{m}}\right)
$$

$\bar{\sigma}_{1}^{T}, \bar{\sigma}_{2}^{T}$ are the principal stresses with $\sigma_{1}^{T}>\sigma_{2}^{T}$, reckoned algebraically. The superscript $T$ indicates total stress due to both loading on the truncated face, see Fig. 1, and hydrostatic pressure. There are two angles for which Eqn. (4) is valid,

$$
\psi_{1,2}=\gamma_{1} \pm\left[\frac{1}{4} \pi-\phi\left(\bar{\sigma}_{\mathrm{m}}\right) / 2\right] ; \tan \phi\left(\bar{\sigma}_{\mathrm{m}}\right)=\mu\left(\bar{\sigma}_{\mathrm{m}}\right)
$$

where $\gamma_{1}$ is the angle between the normal to the first principal plane and the $x$-axis. It is important to note that the interpretation of the angles $\psi_{1.2}$ in terms of fracture direction is unclear at present. The authors do not believe, as is commonly interpreted, that these angles define the fracture directions, per se. The Mohr planes defined by these angles are shown on Fig. 4, and clearly, are not consistent with known "chipping" behavior. The interpretation of Ref. [1], namely that these planes represent directions of critically oriented Griffith cracks, is also not totally consistent here since the Mohr criterion assumes that cracks have already coalesced. However, it can be shown that these directions are close to those predicted by the Griffith theory.

If the total stress is divided into its component parts 


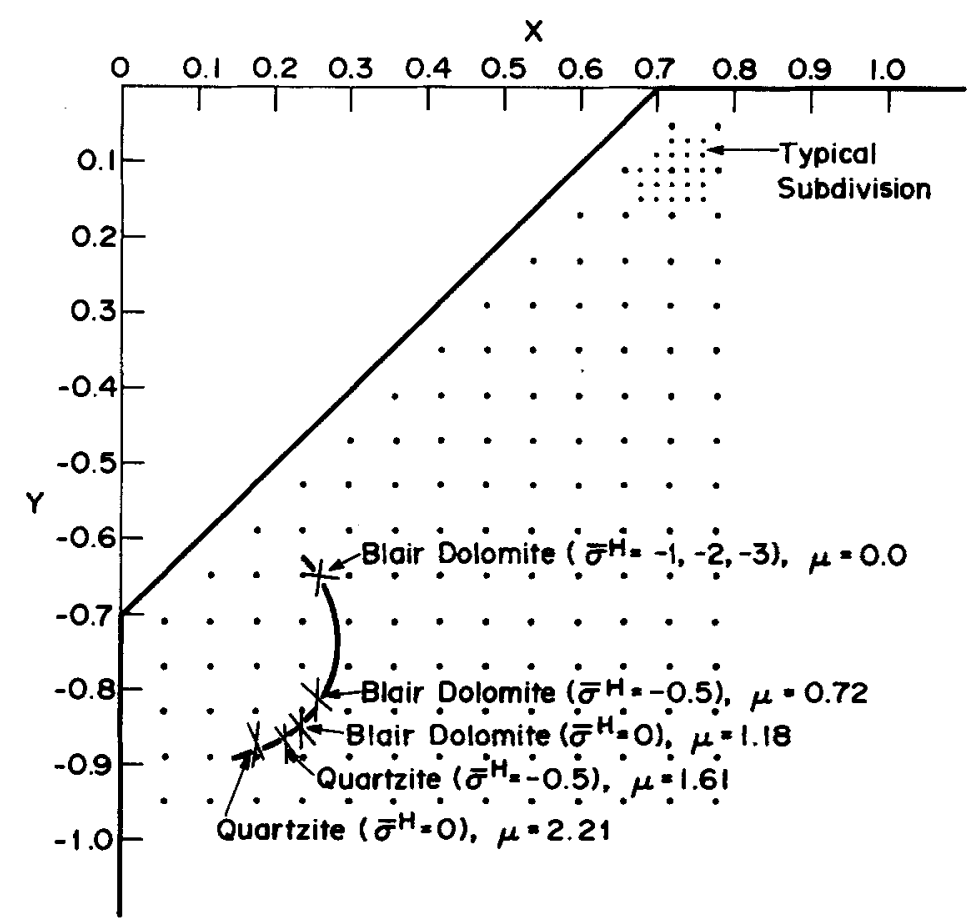

Figure 4. Fracture initiation points for Blair dolomite and quartzite; $m=5, \mu_{f}=0.0$.

$$
\begin{aligned}
& \bar{\sigma}_{1}^{T}=\bar{\sigma}_{1}+\bar{\sigma}^{H} \\
& \bar{\sigma}_{2}^{T}=\bar{\sigma}_{2}+\bar{\sigma}^{H}
\end{aligned}
$$

(where $\bar{\sigma}^{H}$ is the confining pressure) and substituted into Eqn. (4), the following is obtained

$$
\left[\mu\left(\bar{\sigma}_{\mathrm{m}}\right) / 2\right]\left(\bar{\sigma}_{1}+\bar{\sigma}_{2}\right)+\left[1+\mu^{2}\left(\bar{\sigma}_{\mathrm{m}}\right)\right]^{\frac{1}{2}}\left(\bar{\sigma}_{1}-\bar{\sigma}_{2}\right) / 2=C\left(\bar{\sigma}_{\mathrm{m}}\right)-\mu\left(\bar{\sigma}_{\mathrm{m}}\right) \bar{\sigma}^{H}
$$

Nondimensionalizing $\bar{\sigma}_{1}, \bar{\sigma}_{2}$ with respect to $P / L$ (see Fig. 1), i.e. $\sigma_{1}=\bar{\sigma}_{1} L / P, \sigma_{2}=\bar{\sigma}_{2} L / P$, (7) becomes:

$$
P / L\left\{\frac{\mu\left(\bar{\sigma}_{\mathrm{m}}\right)}{2}\left(\sigma_{1}+\sigma_{2}\right)+\frac{\left[1+\mu^{2}\left(\bar{\sigma}_{\mathrm{m}}\right)\right]^{\frac{1}{2}}}{2}\left(\dot{\sigma}_{1}-\sigma_{2}\right)\right\}=C\left(\bar{\sigma}_{\mathrm{m}}\right)-\mu\left(\bar{\sigma}_{\mathrm{m}}\right) \bar{\sigma}^{H}
$$

A "fracture function" is now defined:

$$
\begin{aligned}
& K\left(\bar{\sigma}_{1}^{T}, \bar{\sigma}_{2}^{T} ; \mu\left(\bar{\sigma}_{\mathrm{m}}\right), C\left(\bar{\sigma}_{\mathrm{m}}\right)\right)=\frac{P}{L} \\
& =\frac{2\left[C\left(\bar{\sigma}_{\mathrm{m}}\right)-\mu\left(\bar{\sigma}_{\mathrm{m}}\right) \bar{\sigma}^{H}\right]}{\mu\left(\bar{\sigma}_{\mathrm{m}}\right)\left(\sigma_{1}+\sigma_{2}\right)+\left[1+\mu^{2}\left(\bar{\sigma}_{\mathrm{m}}\right)\right]^{\frac{1}{2}}\left(\sigma_{1}-\sigma_{2}\right)} .
\end{aligned}
$$

This fracture function has the following physical interpretation. It is that value of $P / L$ necessary to initiate fracture at a given point in the field. Clearly, the minimum value of $K\left(K_{\min }\right)$ in the field is where the actual fracture begins.

To find $K$ the stress field $\sigma_{1}, \sigma_{2}$ must first be known. Following Ref. [1] a traction distribution (due to the "wedge" force) is assumed: 


$$
\begin{aligned}
& t_{n}= \begin{cases}0 & \text { on DB } \\
p(\xi / L)^{m} \cdot\left(1-\frac{\cos 2 \pi \xi}{L}\right) & \text { on BA } \\
0 & \text { on AC }\end{cases} \\
& t_{s}= \begin{cases}0 & \text { on DB } \\
\mu_{f} t_{n}=p \mu_{f}(\xi / L)^{m}\left(1-\frac{\cos 2 \pi \xi}{L}\right) & \text { on BA } \\
0 & \text { on AC }\end{cases}
\end{aligned}
$$

where $t_{n}, t_{s}$ are the normal and tangential traction components, $\xi$ a coordinate on BA defined in Fig. 1 and $\mu_{f}$ the coefficient of friction between wedge and rock. The exponent, $m$, is a form parameter which for increasing value gives a more asymmetric and concentrated traction distribution. Values of $m=5$ and $\mu_{f}=0$ are used throughout the analysis. These are reasonable approximations for the traction distribution due to a penetrating wedge shaped tool. The coefficient, $p$, is a scalar pressure which can be related to the half wedge force $P$ as follows :

$$
p=\frac{P \cos \phi_{f}}{L \sin \left(\theta+\phi_{f}\right) \int_{0}^{1} \eta^{m}(1-\cos 2 \pi \eta) \mathrm{d} \eta}
$$

where $\theta$ is the half wedge angle (truncation angle) and $\phi_{f}$ is the friction angle; $\tan \phi_{f}=\mu_{f}$. For $p$ defined by Eqn. (11) all traction distributions (any value of $\phi_{f}, m$ ) add up to the same value of $P / L$ (vertical "force" component).

The stress field (before fracture has started) represents a linear calculation and an integral equation procedure, outlined in detail in references $[1,2]$, can be used. For brevity, this is not repeated here.

With $\sigma_{1}, \sigma_{2}$ known throughout the field for a given traction distribution for which $P / L=$ $1, K_{\min }$ can be found using the following iteration equations:

$$
\begin{aligned}
& K^{(n)}=(P / L)^{(n)}=\frac{2\left[C^{(n-1)}\left(\bar{\sigma}_{\mathrm{m}}^{(n-1)}\right)-\mu^{(n-1)}\left(\bar{\sigma}_{\mathrm{m}}^{(n-1)}\right) \bar{\sigma}^{H}\right]}{\mu^{(n-1)}\left(\bar{\sigma}_{\mathrm{m}}^{(n-1)}\right)\left(\sigma_{1}+\sigma_{2}\right)+\left[1+\left(\mu^{(n-1)}\left(\bar{\sigma}_{\mathrm{m}}^{(n-1)}\right)\right)^{2}\right]^{\frac{1}{2}}\left(\sigma_{1}-\sigma_{2}\right)} \\
& \bar{\sigma}_{\mathrm{m}}^{(n)}=\frac{1}{2}\left(\sigma_{1}+\sigma_{2}\right)(P / L)^{(n)}+\bar{\sigma}^{H} \\
& \bar{\tau}^{(n)}=\Sigma_{0 \leqslant i \leqslant r} \alpha_{i}\left(\bar{\sigma}_{\mathrm{m}}^{(n)}\right)^{i} \\
& \bar{\sigma}^{(n)}=\Sigma_{0 \leqslant i \leqslant r} \beta_{i}\left(\bar{\sigma}_{\mathrm{m}}^{(n)}\right)^{i} \\
& \mu^{(n)}=\left(\bar{\sigma}^{(n)}-\bar{\sigma}_{\mathrm{m}}^{(n)}\right) / \bar{\tau}^{(n)} \\
& C^{(n)}=\bar{\tau}^{(n)}+\mu^{(n)} \bar{\sigma}^{(n)} .
\end{aligned}
$$

where the superscripts in parentheses represent the iteration cycle number. Note that $\sigma_{1}, \sigma_{2}$, $\vec{\sigma}^{H}, \alpha_{i}, \beta_{i}$ are constants throughout the iteration. Assuming initially $(n=1), \mu^{(0)}=0, C^{(0)}=C_{A}$ (the appropriate asymptotic value of the Mohr envelope, see Fig. 3$)^{*}, K^{(1)}$ is found directly from Eqn. (12a). This value of $K^{(1)}$ determines a new mean stress $\bar{\sigma}_{\mathrm{m}}^{(1)}$ from Eqn. (12b), which in turn determines $\bar{\tau}^{(1)}, \bar{\sigma}^{(1)}$ from Eqns. (12c, d) and finally the new constants $\mu^{(1)}$, $C^{(1)}$ from Eqns. (12e, f). This iteration proceeds until convergence is obtained, namely

$$
\left(\left|K^{(n)}-K^{(n-1)}\right|\right) /\left|K^{(n-1)}\right|<\varepsilon
$$

* Beginning the iteration from the asymptotic value of the Mohr envelope avoids certain numerical difficulties, i.e. too large an initial value of $\mu$ may result in an unbounded first iterant. 
where $\varepsilon$ usually is selected to be 0.01 .

This iteration procedure should take place at every point in the field with that point at which $K$ is minimum being the fracture initiation point. To implement this numerically those points shown as dots on Fig. 4 where the initially selected field points. ${ }^{*}$ The iteration procedure was done at all of these points and the location and value of $K_{\min }$ found. The field was then subdivided in the vicinity of this point, as shown in Fig. 4, and the iteration repeated for this smaller field. The new value and location of $K_{\min }$ is the one finally selected. The computer program which does both the stress field calculation and $K_{\min }$ iteration procedure is found in Ref. [10].

\section{Discussion of numerical results}

Numerical results for the two materials considered, namely, Blair dolomite and quartzite, are summarized in Table 2, and in Figs. 4-6. The confining pressures considered in these results, i.e. zero to three kilobars, represent moderate pressures and the materials are still in their brittle state, see Robertson [8].

Fracture initiation locations for the various cases are shown in Fig. 4. As the confining pressure increases the fracture initiation point approaches a limiting point nearer the surface. This indicates a decreasing "chip" size with increasing confining pressure. Similar results have been noted experimentally by Gnirk and Cheatham [9]. The force necessary to initiate fracture also approaches a limiting value as confining pressure increases as is seen in Table 2 . An important result is that fracture initiation location for a given traction distribution is solely dependent on $\mu\left(\bar{\sigma}_{\mathrm{m}}\right)$ (location on the Mohr envelope) $\star \star \star$ The small differences in fracture initiation point for Blair dolomite and quartzite at low confining pressure is due to differences in the slope of their respective Mohr envelope at low mean stress. Differences in the two materials show up in the relative magnitude of the forces required to initiate fracture $\left(K_{\min }\right)$, see Table 2. Mohr envelope intercepts of the various fracture initiation points of Fig. 4 are shown in Fig. 3 for Blair dolomite.

Effects of wedge angle (truncation angle) on the magnitude of the fracture initiation force for Blair dolomite can also be seen in Table 2. As expected, fracture initiation forces increase with increasing wedge angle. It is interesting to note that for all three wedge angles (and

TABLE 2

Fracture initiation results for Blair dolomite and quartzite; $m=5, \mu_{f}=0.0$.

\begin{tabular}{lcccc}
\hline Material & $\theta$ & $\bar{\sigma}^{H}(\mathrm{~kb})$ & $K_{\min }$ & $\bar{\sigma}_{\mathrm{m}}(\mathrm{kb})$ \\
\hline Blair dolomite & $45^{\circ}$ & -3.0 & 4.185 & -11.3 \\
& & -2.0 & 4.185 & -10.3 \\
& & -1.0 & 4.185 & -9.3 \\
& & 0.5 & 3.946 & -4.9 \\
& & 0.0 & 2.708 & -2.65 \\
\cline { 2 - 4 } & $30^{\circ}$ & -2.0 & 3.035 & -10.4 \\
\cline { 2 - 4 } & $60^{\circ}$ & -2.0 & 4.774 & -9.5 \\
\hline \multirow{2}{*}{$45^{\circ}$} & -0.5 & 5.278 & -5.25 \\
& & 0.0 & 2.953 & -2.48 \\
\hline
\end{tabular}

* It is necessary to have $K$ throughout the field for later comments on fracture propagation.

$\star \star T h i s$ conclusion is consistent with the results of reference [1], where the dependence on $\mu$ is discussed in more detail. 


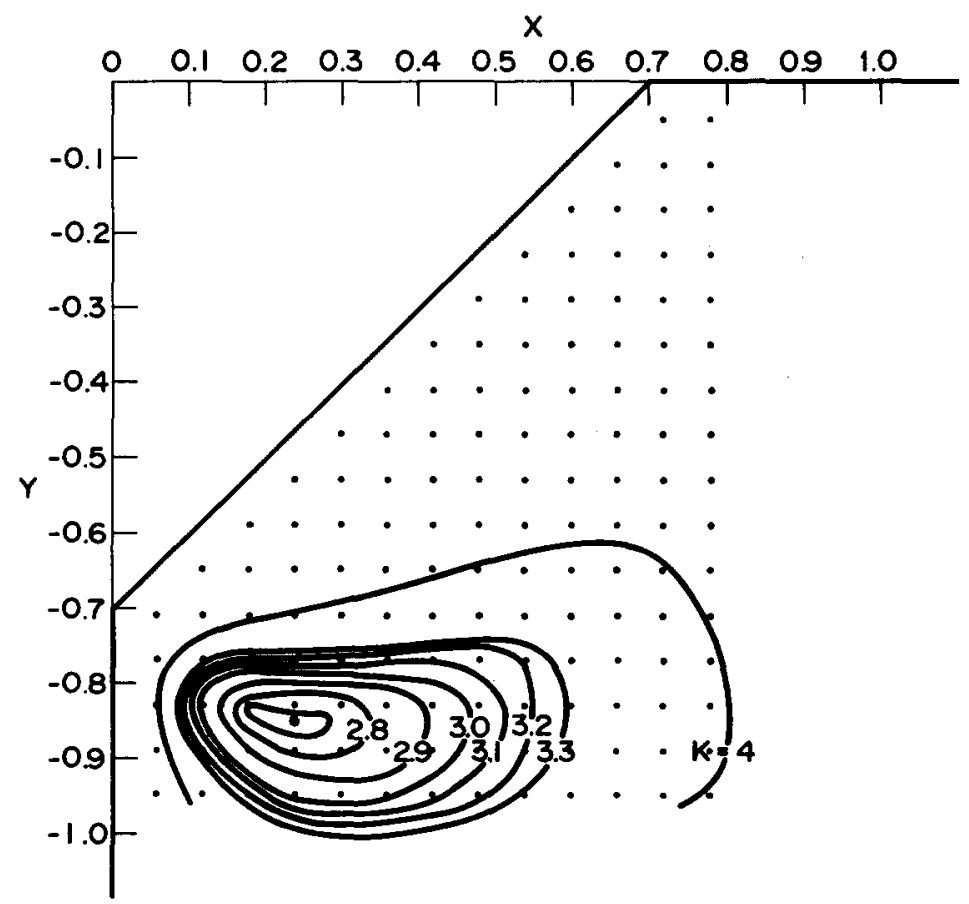

Figure 5. Contour map of fracture function for Blair dolomite at zero confining pressure.

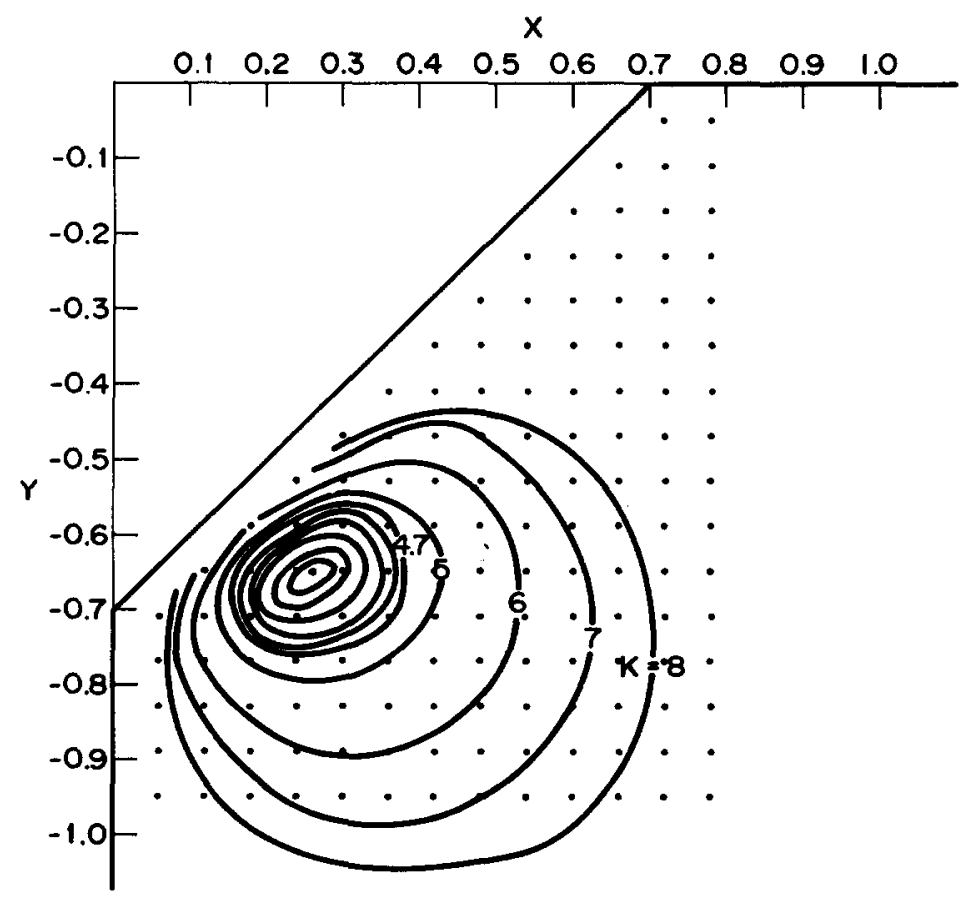

Figure 6. Contour map of fracture function for Blair dolomite at moderate confining pressure $(3 \mathrm{~kb})$.

$\bar{\sigma}^{H}=-2 \mathrm{~kb}$ ) the location of the fracture initiation point was identical (within the range of accuracy of the subdivision) relative to the truncated face. This is expected, however, since the fracture initiation point is somewhat removed from the boundaries DB and AC of Fig. 1. 
The analysis (determination of $K$ throughout the field) can be used to predict initial propagation of the fracture also. In Figs. 5 and 6 contour maps of $K$ for Blair dolomite at zero and three kilobars confining pressure are shown. Following Ref. [1] it is proposed that the initial propagation of the fracture follows the minimum gradient of the contour plot. An interesting result is that this proposed fracture path is well defined at zero confining pressure, Fig. 5, but less so at higher confining pressure, Fig. 6. This would indicate more ambiguity in chipping behavior at higher confining pressures. This has also been seen experimentally by Gnirk and Cheatham [9].

\section{Acknowledgement}

The authors gratefully acknowledge the financial support of the National Science Foundation under Grant No. GK 37289.

\section{REFERENCES}

[1] D. L. Sikarskie and N. J. Altiero, The Formation of Chips in the Penetration of Elastic-Brittle Materials (Rock), Journal of Applied Mechanics, 40, 3; Trans. ASME, 95, Series E, (1973) 791-798.

[2] R. Benjumea and D. L. Sikarskie, On the Solution of Plane, Orthotropic Elasticity Problems by an Integral Method, Journal of Applied Mechanics, 39, Trans ASME, 94, Series E, (1972) 801-808.

[3] B. Paul, Macroscopic Criteria for Flow and Fracture, Fracture: An Advanced Treatise, Vol. II, ed., Liebowitz, H., Academic Press, New York and London (1968) Chapter 4.

[4] Z. T. Bieniawski, Mechanism of Brittle Fracture of Rock, International Journal of Rock Mech. Min. Sci., 4, (1967) 395-430.

[5] W. F. Brace, Brittle Fracture of Rocks, State of Stress in the Earth's Crust, ed. W. Judd, Elsevier, New York (1964).

[6] W. F. Brace, E. Silver, K. Hadley and C. Goetze, Cracks and Pores: A Closer Look, Science, 178 (1972) $162-164$.

[7] B. Carnahan, H. A. Luther and J. O. Wilkes, Applied Numerical Methods, John Wiley and Sons, Inc., New York (1969) 574-584.

[8] E. C. Robertson, Experimental Study of the Strength of Rocks, Bulletin of the Geological Society of America, 66 (1955) 1275-1314.

[9] P. F. Gnirk and J. B. Cheatham, An Experimental Study of Single Bit-Tooth Penetration into Dry Rock at Confining Pressures of 0 to 5000 psi, Society of Petroleum Engineers Journal. AIME Trans., 234 (1965) 117-130.

[10] N. J. Altiero and D. L. Sikarskie, Fracture Initiation in Elastic-Brittle Materials Having Nonlinear Fracture Envelopes, ORA Report No. 011909-1-T, The University of Michigan, (1974).

\section{RÉSUMÉ}

On met en évidence une théorie pour la détermination de l'amorçage d'une rupture et du début de la propagation d'une rupture dans des matériaux fragiles élastiques caractérisés par une courbe enveloppe de rupture de Mohr non linéaire. Cette théorie est appliquée à un problème de valeur aux limites, à savoir un quart de plan tronqué soumis, à la périphérie de la troncature, à une distribution arbitraire de charges de traction et de pressions de maintien. Ce problème évoque la phase de formation d'un copeau lors de la pénétration d'un outil en forme de coin dans un matériau fragile élastique. Des résultats numériques sont obtenus dans le cas de deux roches: une dolomite de Blair et une quartzite.

Ces résultats indiquent que, lorsque la pression de maintien s'accroît, on atteint une condition limite à la fois pour la localisation et la tension d'amorçage de la rupture. Cette localisation est plus voisine du bord libre que le point d'amorçage correspondant à des pressions de maintien plus basses, ce qui se traduirait par des copeaux plus petits. On trouve également que le début de propagation de la rupture est plus difficile à définir clairement lorsque les pressions de maintien sont plus élevées. Ces deux types de résultats ont été confirmés expérimentalement.

\section{ZUSAMMENFASSUNG}

Man erläutert eine Theorie zur Bestimmung der Brucheinleitung und der Anfangsbruchausdehnung in elastisch spröden Materien mit unlinearen Mohrschenbruchhüllkurven. Diese Theorie wird auf ein spezifisches Grenzwertproblem angewandt, z.B. eine abgeschnittene Viertelebene mit einer willkürlichen Zugkraftverteilung an der abgeschnittenen Grenze und mit veränderlichem EinschlieBungsdruck. Dieses Problem simuliert die Aufbrechphase des Eindringens eines keilförmigen Instrumentes in ein elastisch sprödes Material. Numerische Ergebnisse werden für zwei Felsmaterien, Dolomit und Quarzit gegeben.

Die Ergebnisse zeigen daß für anwachsender Einschließungsdruck eine Grenzbedingung sowohl für den Brucheinleitungsort, als für die Kraft gegeben wird. Diese Grenzpunkte sind näher zur Grenze als die Brucheinleitungspunkte unter niedrigem Einschließungsdruck, die kleinere Splitter erzeugen. Es ergibt sich auch daß die Anfangsrißausdehnung sich weniger klar bei höherem Einschließungsdruck anzeigt. Beide Ergebnisse haben sich durch Versuche bestätigt. 